05

\title{
Акустооптическое сложение мощностей импульсных некогерентных лазеров
}

\author{
(C) С.Н. Антонов \\ Институт радиотехники и электроники \\ им. В.А. Котельникова РАН, \\ 141190 Фрязино, Россия \\ e-mail: olga-ant@yandex.ru
}

Поступила в редакцию 09.01.2018 г.

В окончательной редакции 10.04.2018 г.

\begin{abstract}
Предложен и экспериментально обоснован метод сложения мощностей импульсных некогерентных однотипных (одинаковых) лазеров, основанный на временном уплотнении импульсов. Метод базируется на использовании акустооптического дефлектора, который переключает излучение из различных источников в один выходной канал синхронно с излучением в данном канале. Существенно, что мощность итогового выходного излучения принципиально равна сумме мощностей входных излучателей, а угловые и координатные характеристики выходного луча равны исходным источникам. Эксперименты проводились с одномодовыми полупроводниковыми лазерами на длине волны $1.3 \mu \mathrm{m}$ с помощью дефлектора на базе кристалла $\mathrm{TeO}_{2}$. Метод применим для сложения волоконно-оптических, полупроводниковых и твердотельных лазеров. Проведена оценка основных взаимосвязанных параметров.
\end{abstract}

DOI: $10.21883 /$ OS.2018.09.46555.3-18

\section{Введение}

Сложение мощностей однотипных (одинаковых) лазерных источников в один канал - интересная и технически важная задача. Заданные условия такого сложения следующие: источники некогерентны, принципиально мощность выходного луча равна сумме мощностей исходных источников, а угловые и координатные характеристики должны остаться неизменными. Сложение, с указанными требованиями, возможно только для когерентных исходных источников [1]. В то же время, существует ошибочное мнение, что его можно реализовать для непрерывных некогерентных источников [2].

Импульсные лазеры широко используются в современной науке и технике. Это оптическая связь, навигация, системы позиционирования, обработка материалов. Одним из основных параметров лазеров является интегральная (средняя) выходная мощность. Для полупроводниковых лазеров ограничение мощности связано с тепловыми эффектами, для волоконно-оптических как c тепловыми ограничениями в диодах накачки, так и с нелинейными эффектами в волоконных световодах (BC).

Задача работы заключается в сложении мощности нескольких однотипных импульсных некогерентных лазерных источников в один выходной канал с целью повышения суммарной мощности импульсного лазерного излучения. Существенно, чтобы оптические характеристики (линейная и угловая апертуры) выходного канала были идентичны характеристикам исходных лазеров, а принципиальные потери оптической мощности отсутствовали.

\section{Принцип сложения мощности импульсных лазеров}

Принцип суммирования основан на временном уплотнении, когда время „молчания“ первого лазера заполняется последующими.

Сложение осуществляется акустооптическим методом (AО), а именно АО дефлектором (АОД) - устройством, предназначенным для отклонения (сканирования) луча фиксированного направления в некотором угловом диапазоне путем изменения частоты управляющего сигнала [3-6].

В данном случае предлагается использовать АОД в „обратном“ режиме - дефлектор не переключает свет одного направления в несколько, а переключает свет от нескольких разнонаправленных источников в единственный канал - единственное направление. Правомерность такого использование АОД основано на фундаментальном физическом принципе - оптической взаимности АО. При этом очевидно, что все теоретические выкладки и технические параметры для дефлектора аналогичны и также применимы для АО сумматора.

При общности принципа для конкретизации далее будем полагать, что лазеры одномодовые и пиктелированы (имеют волоконные выходы) с одномодовыми ВС.

Схема АО сложения представлена на рис. 1.

Выходные торцы $B C$ расположены в один ряд, образуя линейную матрицу. Линзой $L 1$ выходные лучи коллимируется в диаметр $D$ и направляется на АОД, на выходе которого установлена линза $L 2$, фокусирующая свет в торец входного $B C$.

Принцип работы поясняется на рис. 2. 

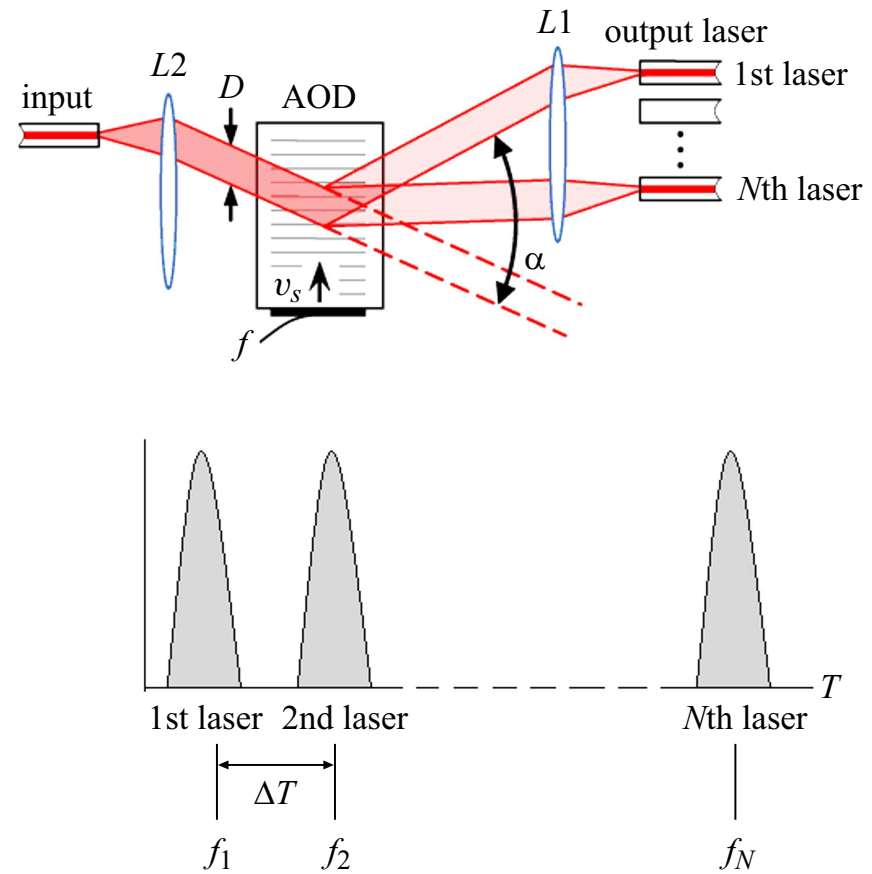

Рис. 1. Иллюстрация принципа АО сложения мощностей лазеров.

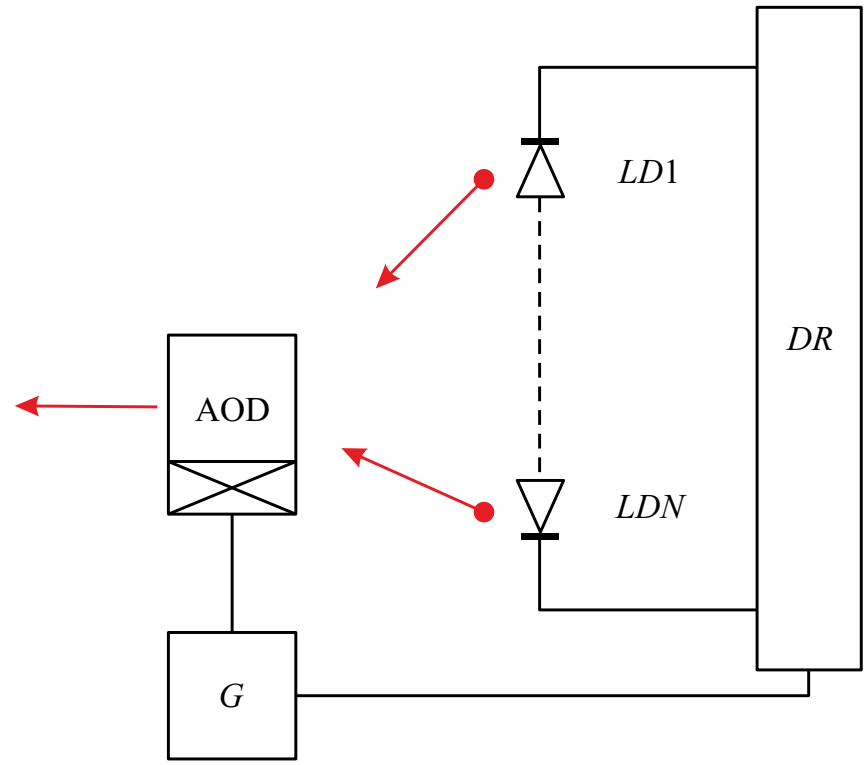

Рис. 2. Принципиальная схема АО сложения.

Лазерные источники $L D 1-L D N$ управляются процессорным драйвером $D R$ и включаются попеременно с некоторым сдвигом во времени $\Delta T$, обеспечивающим временное разделение импульсов. Последовательное включение лазеров синхронизовано с генератором сигнала $G$, который управляет работой АОД. Каждому лазеру соответствует свое значение частоты, которая установлена таким образом, чтобы дифрагированный луч всегда был направлен на входной $B C$.

\section{Оценка основных параметров}

Эксперименты проводились на базе наиболее широко используемого в дефлекторах кристалла парателлурита $\left(\mathrm{TeO}_{2}\right)$ с дифракцией на медленной акустической волне, распространяющейся под углом $6^{\circ}$ к кристаллографической оси [110] со скоростью $0.65 \cdot 10^{6} \mathrm{~mm} / \mathrm{s}$. Расчеты и эксперимент соответствуют этой ситуации.

Основными взаимосвязанными параметрами сумматора мощности являются быстродействие (время переключения) $\tau$ и число каналов $N$, находящиеся в компромиссном соотношении друг с другом. Так, увеличение $N$ снижает быстродействие. Оценим их численные значения.

Дифракционный угол отклонения (рассеяния) $\alpha$ :

$$
\alpha=f \lambda / v
$$

где $f$ - частота ультразвука в АОД, $\lambda$ - длина волны света, $v$ - скорость звука в $\mathrm{TeO}_{2}$.

Апертура $D$ выбирается исходя из заданного быстродействия, характеризуемого $\tau-$ временем, за которое акустическая волна проходит заданную апертуру света:

$$
D[\mathrm{~mm}]=0.65 \tau[\mu \mathrm{s}] .
$$

К примеру, для времени переключения $6 \mu$ s апертура составляет $D=4 \mathrm{~mm}$. Максимальное (предельное) число каналов $N_{m}$ определяется максимальной рабочей полосой частот АОД $\Delta f$ и значением $D$ :

$$
N_{m}=\Delta f \cdot D / v
$$

Диапазон рабочих частот практических дефлекторов находится в диапазоне $15-30 \mathrm{MHz}$. Таким образом, для $D=4 \mathrm{~mm}$ и $\Delta f=20 \mathrm{MHz}$ получаем $N_{m} \sim 120$, если бы ВС были расположены друг от друга на расстоянии (аналогично ситуации классического дефлектора), соответствующем критерию Релея. Очевидно, что практическим ограничением числа каналов является плотность упаковки ВС в матрице.

Световедущие жилы ВС удалены друг от друга на некоторое расстояние по двум причинам. Во-первых, чисто технологически и, во-вторых, в силу „паразитного“ проникновения света в соседние каналы. Величина этого проникновения определяется плотностью упаковки ВС в матрице, т.е. отношением расстояния между соседними волокнами $R$ к диаметру световедущей жилы волокна $d$ (рис. 3).

Выбранные быстродействие, реализуемая полоса рабочих частот АОД и плотность упаковки ВС в матрице определяют максимальное количество каналов:

$$
N=(d / R) \cdot \Delta f \cdot \tau
$$

Для используемого в эксперименте АОД [7] плотность упаковки 3 и в полосе частот АОД $20 \mathrm{MHz}$ для однокоординатного случая имел $N \sim 7$ каналов. 
При использовании двухкоординатной схемы (рис. 4) количество выходных ВС каналов составит $N^{2}$.

При этом за первым АОД стоит второй, ориентированный ортогонально первому. Первый и второй АОД отклоняют свет во взаимно ортогональных направлениях. Углы отклонения управляются независимо, что позволит адресовать свет из любого ВС двумерной матрицы.

\section{Экспериментальные результаты}

Практическая реализация АO суммирования мощностей импульсных лазеров была произведена на изготовленном ранее двухкоординатном переключателе волоконно-оптических каналов [7]. Этот переключатель был предназначен для переключения света из одного выходного ВС в матрицу входных ВС. В нашем случае, как указывалось, в силу взаимности АО эффекта работа велась „наоборот“. На рис. 5 представлена фотография.

Принципиальной особенностью переключателя является его поляризационная нечувствительность [8].

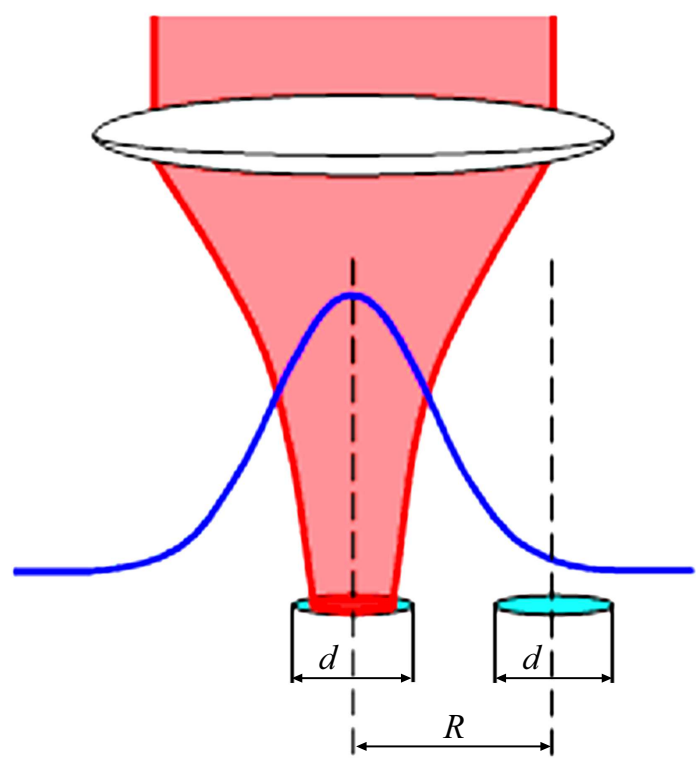

Рис. 3. Параметры упаковки ВС.

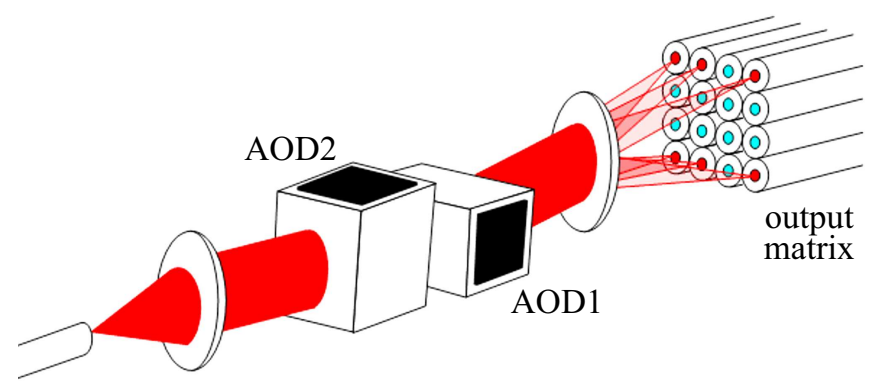

Рис. 4. Схема двухкоординатного сумматора мощности лазеров.

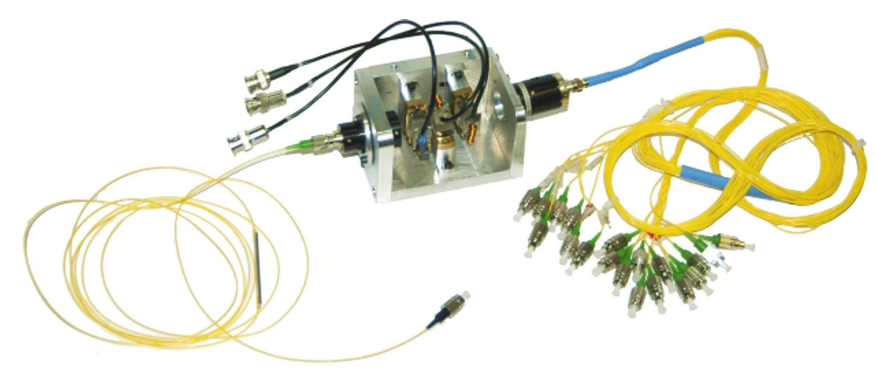

Рис. 5. Внешний вид используемого переключателя. Его параметры: 19 каналов, ВC разъемы типа FC-PC, диаметр коллимированного света на кристаллах $\mathrm{TeO}_{2}-4 \mathrm{~mm}$, тип ВС - одномодовые, диапазон длин волн $1.3-1.5 \mu \mathrm{m}$, потери вход-выход $3 \mathrm{~dB}$, мощности управления: $1 \mathrm{~W}(1.3 \mu \mathrm{m}), 2 \mathrm{~W}$ $(1.5 \mu \mathrm{m})$.

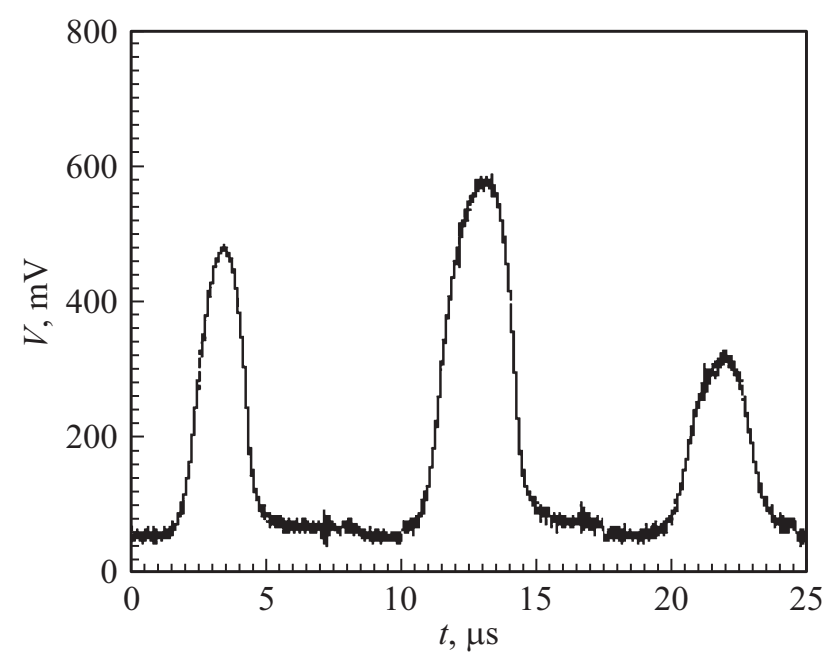

Рис. 6. Выходной сигнал как функция времени.

Эксперименты проводились с тремя одномодовыми лазерными диодами FPL-1310-8DL-2. Лазеры работали в импульсном режиме, выходная мощность каждого $2 \mathrm{~mW}$, длина волны $1.3 \mu \mathrm{m}$.

На рис. 6 показан итог сложения лазерных излучений - сигнал на выходе сумматора - электронная фотография с экрана осциллографа.

Для наглядности эффекта сложения амплитуда и длительность импульсов на каждом лазере устанавливались различными.

Расстояние между импульсами $10 \mu \mathrm{s}$ в данном случае выбрано таким, чтобы быстродействие АОД (6 $\mu \mathrm{s})$ обеспечило переключение частоты.

\section{Заключение}

Предложен и практически обоснован АО метод сложения мощностей импульсных некогерентных лазеров. Метод основан на временном уплотнении. Практически реализовано суммирование трех полупроводниковых лазеров на длине волны $1.3 \mu \mathrm{m}$ с помощью дефлектора 
на основе кристалла $\mathrm{TeO}_{2}$. Существенно, что при таком сложении не меняются угловые и координатные характеристики исходных источников. В силу того, что АО приборы управляют лазерным излучением большой мощности, результат сложения может быть весьма значителен. Метод пригоден для сложения мощностей волоконнооптических, полупроводниковых и твердотельных лазеpoв.

Работа выполнена в рамках госзаказа ФИРЭ РАН.

\section{Список литературы}

[1] Держсавин С.И., Дюкель О.А., Лындин Н.М. // Квант. электрон. 2012. Т. 42. № 6. С. 561-564.

[2] Проклов В.В. и др. // Радиотехника и электроника. 2013. T. 58. № 9. C. $905-915$

[3] Магдич Л.Н., Молчанов В.Я. Акустооптические устройства и их применение. М.: Советское радио, 1978. 111 с.

[4] Антонов С.Н. // ЖТФ. 2016. Т. 86. № 1. С. 136-139.

[5] Балакший В.И., Парыгин В.Н., Чирков Л.Е. Физические основы акустооптики. М.: Радио и связь, 1985.

[6] Антонов С.Н. // ЖТФ. 2016. Т. 86. № 10. С. 155-158.

[7] Antonov S., Vainer A., Proklov V., Rezvov Y. // Appl. Opt. 2009. V. 48. № 7. P. 171-181.

[8] Антонов С.Н., Никируй Э.Я., Вайнер А.В. Способ двухкоординатного отклонения оптического излучения. Патент RU (11) 2355007. 